\title{
TOLERANCE OF HETERACRIS LITTORALIS (ORTHOPTERA: ACRIDIDAE) TO THE TOXIC PLANT, NERIUM OLEANDER (APOCYNACEA)
}

\author{
By \\ MOHAMED MOHAMED ELSHAZLY, NIRVINA ABDEL-RAOUF GHAZAWY, \\ KHALED MOHAMED ABDEL RAHMAN, GHADA MOHAMED ELBASSIONY \\ and MAMDOUH IBRAHIM NASSAR \\ Department of Entomology ${ }^{1}$, Faculty of Science, Cairo University, Giza P.O. Box \\ 12613, Egypt ( ${ }^{*}$ Correspondence: mamdouh@sci.cu.edu.eg, mmnassar2002 \\ @yahoo.com Mobile: 00201009792546, ORCID: 0000-0002-4624-740X)

\section{Abstract}

Nerium oleander (Apocynacea) is a highly toxic plant that has never been reported to be selected as a food or even as a resting place by any acridid species. The study tested the competence of Heteracrislittoralis (Orthoptera: Acrididae) to tolerate and survive on this plantfor considerable periods, and to resume normal capacity of development and reproduction when favourable food plant became available. Nymphal survival and development were followed by monitoring three cohorts of freshly hatched hoppers. The first cohort fed oleander leaves; the second one (control) fed clover; while the third cohort fed oleander leaves for 35 days, and then switched to clover. Age specific survivorship and reproductive parameters of the adults were followed by monitoring three cohorts of newly fledged adults fed on the same patterns. Moulting was suspended in nymphs fed oleander; when food plant was switched to clover, the insects resumed normal development and reached the adult stage. Adult cohort reared on $N$. oleander exhibited a normal age specific survivorship curve, but ovarian development was suspended. Suspension of ovarian development by $N$. oleander was accompanied by very low indices of food consumption and conversion of digested food into body substance. But, after switching to normal food, clover, the insects resumed normal ovarian development with significant prolonged longevity, and the fecundity was approximately equal to the same parameter in the control cohort. This reflects a strong evolutionary biotic potential against the selective power of plant defense.

Key words: Toxic plant, Development, Reproduction, Plant defense, Insect tolerance

\section{Introduction}

The Mediterranean Splendid Grasshopper, Heteracris littoralis (Rambur) (Orthoptera: Acrididae) is distributed through the Cape Verde Islands across northern Africa to India (Grunshaw, 1991). In Europe, it occurs on the Canary Islands, at the coast of the Iberian Peninsula, in Greece and in Cyprus (Heller, 2013); this grasshopper is a nongraminivorous. Hoppers and adults possess almost the same food taste. Out of several plant species few species including clover, cotton, and bean were found to be favorable as pure diets for survival, development, and reproduction of this grasshopper, with little differences in the growth rates of the hoppers (Ibrahim, 1980). It is generally accepted that secondary plant metabolites are considered as plant defense mechanism against herbivores. Despite the selective force in- volved in the evolution of plant secondary compounds, they act as feeding deterrents, and can be considered as major determinants of host range of phytophagous insects (Bernays and Chapman, 2000).

Oleander, (Nerium oleander: Apocynaceae), is an evergreen urbanite shrub, indigenous to the Indo- Pakistan subcontinent; this plant is widely distributed in the Mediterranean region and subtropical Asia where it is commonly used for ornamental purposes. In Egypt, there are three varieties of $N$. oleander, which can be easily distinguished by the color of the flower (red, pink \& white flowered varieties). Longford and Boor (1996) reported that all parts of the plant are toxic to humans, vertebrates and certain insects; while Siddiqui et al. (1997) cited that several parts of the plant are therapeutically effective in the treatment of some diseases. Re- 
views of the chemistry, pharmacological significance and toxicity of $N$. oleander have been given (Zibbu and Batra, 2010; Hase et $a l, 2017)$. Despite its toxicity and pharmacological activity, $N$. oleander supports a complete terrestrial food web of more than 25 arthropod species, representing 20 families, the majority were insects belonged to different feeding guilds and different orders including Lepidoptera, Diptera, Coleoptera, Hymenoptera, Orthoptera, Homoptera, and Neuroptera (El-Shazly, 2002). However, the plant is protected from several herbivores by its defensive secondary metabolites, e.g. Spodoptera litura (Rao and Chitra, 2000), Schistocerca gregaria (Bagar et al, 2015).

Ecologically, plant as a food resource, is a density-dependent environmental biotic factor; which can be depleted if the population's needs exceeds the available quantities. The unfavourable or toxic plant can be considered as a selective power against insects, if they are forced to devour it confronted with hunger when a favorable plant food resource could not be found. It has been proven that $N$. oleander inhibited moulting in the $4^{\text {th }} \& 5^{\text {th }}$ instar nymphs of Schistocerca gregaria (Bagar et al, 2013); likewise Cyperusiria showed pronounced morphogenetic effects on the nymphal development of the grasshopper Melanopluss anguinipes, and ovaries dissected from females fed $C$. iria were markedly underdeveloped (Toong et al, 1988). However, no attempt has been made to follow the development and survival if a toxic or unfavourable plant fed to the insect is switched to a favorable one. Indeed, this is approached in the present work. The competence of $H$. littoralis was tested to tolerate and survive for considerable periods on $N$. oleander, as a restricted diet; and the capability of the insect to resume normal capacity of development and reproduction, when a favourable food plant became available.

The study aimed to: a) to test possibility of $H$. littoralis nymphs and adults to survive on a restricted diet of $N$. oleander, b) to estimate nutritional indices of newly fledged adults fed restricted diet of $N$. oleander compared to favorable food plant (clover), and c) to test the competence of the insect to resume nymphal development and adult reproductive capacity when supplied with only $N$ oleander for considerable periods, before being switched to a favorable food plant.

\section{Materials and Methods}

Laboratory culture: Adults and nymphs of H. littorals (Rambur, 1838) were collected from the experimental research farm affiliated to the Faculty of Agriculture, Cairo University, in April 2017. Once in the laboratory, a stock culture was maintained as described by Henry (1985). Individuals of both sexes were placed in wire-screened, wood cages $(20 \times 20 \times 30 \mathrm{~cm})$ in a rearing room under controlled conditions $\left(28^{\circ} \mathrm{C} \pm 2,12 \mathrm{~L}\right.$ : $12 \mathrm{D}$, $65 \% \pm 5 \mathrm{RH})$.

The insects were fed with thoroughly washed, fresh leaves of clover, Trifolium alexandrinum. The cages were supplied with a substrate for oviposition that consisted of a plastic container $(15 \mathrm{~cm}$ deep) filled with the sterilized moist sand. Mating and thermoregulation were stimulated with $75 \mathrm{~W}$ bulbs suspended $15 \mathrm{~cm}$ above each cage. Egg-pods were incubated in situ under the same controlled conditions.

Nymphal survival and development were followed by monitoring three cohorts, each of 60-71 freshly hatched individuals. The control cohort fed favorable food (clover). The oleander cohort was raised on restricted diet of oleander leaves to test the tolerance and survival on oleander as a restricted diet; while the third cohort was fed oleander leaves for 35 days, and then switched to normal food (clover) to test the ability of the insect to resume normal development when favorable food became available. The survival and development were monitored daily until the last survivor moulted to adult; while the oleander-fed cohort was monitored until the last survivor died (because oleander leaves inhibited moulting to adult). Each co- 
hort was divided into three groups, kept under controlled conditions of $30^{\circ} \mathrm{C}$, relative humidity of $65 \% \pm 5$ and a photoperiod of 12L:12D.

The rate of development after switching the food plant from clover to $N$. oleander, and vice versa, was observed by raising two groups of newly hatched nymphs $(N=30)$ on restricted diets of either clover or oleander for 23 days, and then the food was altered for 7 days. The insects were weighed and their lengths were measured at suitable intervals.

Nutritional indices of adults: Nutritional indices were determined by gravimetric method on dry weight basis for freshly emerged adults fed oleander leaves compared to control group, fed clover leaves, for 14 days (average preoviposition period of control group). Three replicates, 10 individuals each, were used for both experimental and control groups. The initial fresh food and feces remaining were weighed daily. The quantity of food ingested was determined by subtracting the diet remaining at the end of each experiment from the total weight of fresh diet supplied. To obtain the percentage of dry weight of the food, faces, and insects, 20 specimens for each were weighed, oven-dried $\left(48 \mathrm{~h}\right.$ at $\left.60^{\circ} \mathrm{C}\right)$, and subsequently reweighed. In this study, "natural losses" including biomass changes in substances other than water (carbon dioxide, volatile materials, microbial decay products, etc.) were not measured (Hemati et al, 2012). The indices were calculated according to the formulae (Wa-ldbauer, 1968): Consumption index $(\mathrm{CI})=\mathrm{E} / \mathrm{A}$, Approximate digestibility $(\mathrm{AD})=\mathrm{E}-\mathrm{F} / \mathrm{E}$, Efficiency of conversion of ingested food $(E C I)=P / E$, Efficiency of conversion of digested food $(\mathrm{ECD})=\mathrm{P} / \mathrm{E}-\mathrm{F}$, Growth rate $(\mathrm{GR})=\mathrm{P} / \mathrm{A}^{*} \mathrm{~T}$. $\mathrm{A}=$ mean dry weight of insect over unit time, $\mathrm{E}=$ dry weight of food consumed, $\mathrm{F}=$ dry weight of feces produced, $\mathrm{P}=$ dry weight gained by insect, and $\mathrm{T}=$ duration of feeding period.

Adult lifespan and reproductive biology:
Age-specific survivorship in the adult stage was followed by monitoring three cohorts, each of 50-60 individuals of freshly fledged adults. One of the cohorts was raised on restricted diet of oleander leaves. The $2^{\text {nd }}$ (control cohort) was raised on restricted diet of clover; while the 3rd cohort fed oleander leaves for 45 days, and then switched to normal food (clover). Because this experiment started from adult emergence, cohort survivorship was recorded on normal food plant (clover) before adult emergence; based on nymphal records, survivorship ( $l x$, proportion of individuals surviving from birth to age $x$ ) of each cohort was recorded until the death of last survival in the three cohorts.

Insects of each cohort were segregated in pairs, kept in suitable cages supplied with an ovipositional pot. Reproductive parameters of the cohorts including preoviposition period, longevity, number of egg pods per female, and number of eggs per egg pod were determined. The insects were placed pairwise in wire-screened, aluminium cages $(20 \times 20 \times 30 \mathrm{~cm})$ in a rearing room under controlled conditions of $30^{\circ} \mathrm{C}$, relative humidity of $65 \% \pm 5$ and a photoperiod of 12L:12D. The insects were fed with thoroughly washed, fresh leaves of the desired plant.

\section{Results}

Heteracris littoralis nymphs of the oleander fed cohort could not reach the adult stage, but survived for considerable periods ranged between 17 and 81 days with an average of $48.25 \pm 2.7$ days. In control cohort, the normal progressive nymphal development was achieved and the adult stage was reached through 5-7 instars as previously reported for this species (Ibrahim 1980). The nymphal duration ranged between 28 and 38 days, with an average of $28.42 \pm 2.21$ days and $88.13 \%$ survival. In the 3rd cohort, nymphs tolerated feeding on $N$. oleander without moulting for 35 days. After being switched to normal diet, clover, they started moulting through the successive instars, to reach the adult stage in 53 to 63 days (including 35 days feeding on oleander), with 
an average of $59.5 \pm 2.2$ days and $77.97 \%$ survival.

The progressive increase in live weights and body lengths of $H$. littoralis male nymphs fed oleander or clover were determined for 30 days. No significance $(P>0.05)$ was recorded between weights and lengths of $H$. littoralis cohorts fed on both diets for the first 10 days, then the difference in the average life weight (Fig. 1) and body length (Fig. 2) increased significantly $(P<0.05)$ in the control cohort.

Two groups of newly hatched nymphs were fed on restricted diets of clover and oleander for 23 days, and then food plant was switched for both groups (Figs. $3 \& 4$ ). In the control group, the weight gain of nymphs increased significantly $(P<0.001)$ after 10 days of feeding on clover. After switching the diet to oleander, the weight decreased insignificantly $(P>0.05)$. On the other hand, the weight of nymphs fed oleander for 23 days increased insignificantly $(P>0.05)$ until switching the diet to clover.

Then, the weight of nymphs was not only increased significantly $(P<0.001)$ in one week, but also the nymphs moulted to the next instar (Fig. 3). This was also applied to the body length of the two groups, where the length of the nymphs was significantly $(P<0.001)$ increased twice in one week after switching the diet from the Nerium to clover (Fig. 4).

Nutritional indices of $H$. littoralis raised on restricted diet of oleander, compared to control group (raised on clover), were determined for freshly emerged adults for 14 days (the average preoviposition period of the control group). ECI and ECD values, of $H$. littoralis reared on $N$. oleander were significantly lower than those reared on clover (Table 1). ECI is a general index of an insect's ability to use the food consumed for growth and development, while ECD is an index of the efficiency of conversion of digested food into body substance. The consequences of the low ECI and ECD are the week growth rate (GR), while the relatively high $\mathrm{AD}$ on $N$. oleander (Tab. 1) could be a mechanism where-by the insect body compensates the extremely low value of CI. There were extreme differences in the life weights and body size between males and females of $H$. littoralis. The average life weights of freshly fledged adults are $272.10 \pm 7.08$ and $601 \pm 3.98 \mathrm{mg}$ for males and females, respectively; while average lengths of the two sexes were $23.60 \pm 0.38$ and $37.8 \pm 0.56 \mathrm{~mm}$, for males and females, respectively. During the period of sexual maturation, the females raised on normal diet, clover, increased progressively in weight, due to ovarian maturation and the formation of egg pods, to reach $1.33 \pm 0.04 \mathrm{mg}$ just before oviposition, while females raised on oleander have shown a slight increase in their live weights during the same period due to the suspension ovarian development (Fig. 5).

The main reproductive parameters of experimental and control cohorts were given (Tab. 2). Adult cohort fed on N. ole-ander from adult emergence, tolerated the toxic effect of the plant and exhibited fairly long lifespans compared to the control cohort (Tab. 2). Meanwhile, the cohort fed as adult on $N$. oleander for 45 days, and then switched to clover, exhibited prolonged lifespans compared to control cohort. The mean longevity of adult males and females fed oleander for 45 days, before being switched to clover, were 1.4 and 1.68 folds more than control male and female groups, respectively. Survivorship curve of the cohort fed on restricted diet of oleander was more or less similar to control cohort, where the mortality was concentrated in the final weeks of adulthood. However, survivorship curve of the cohort fed $N$. oleander for 45 days, and switched to clover showed a more regular death rate (Fig. 6).

Females fed on clover showed well developed ovary (Fig. 7A). Average length of the ovary just before oviposition was $28.9 \pm 2.42$ $\mathrm{mm}$ and full number of ovarioles was $51.3 \pm$ 4.27. By day 15 after emergence, all females 
have already laid their first egg-pod. On the other hand, those fed Nerium leaves failed to develop ovaries. The size of ovaries remainned small as the newly emerged female (Fig. 7B). These females were also unable to oviposit even after a long period ( 45 days). The average number of ovarioles in such females was 25.2 \pm 2.57 (Fig. 7C). The two exceptions were observed in two females ( $N=30$ individuals), where one egg pod was laid by each of them after $53 \& 61$ days of their adult lives, respectively. However, the egg pods were unfertile and didn't hatch.
The size of eggs produced in such ovaries was relatively small as compared with normal eggs (Fig. 7D \& E). In the cohort fed $N$. oleander for 45 days, sexual maturation and oviposition were suspended until the insects were provided with the favorable food, clover, and then the insects resumed normal development and started to lay eggs within 4 to 8 days; the average number of egg pods per female and the average fecundity were almost the same as the control cohort.

The details were given in tables $(1 \& 2)$ and figures (1, 2, 3, 4, 5, $6 \& 7)$.

Table1: Nutritional indices for grasshopper H. littorallis adults fed on N. oleander and T. alexandrinum.

\begin{tabular}{|c|c|c|c|c|}
\hline \multirow{2}{*}{ Indices } & \multicolumn{2}{|c|}{ Nerium-fed adults } & \multicolumn{2}{c|}{ Trifolium-fed adults } \\
\cline { 2 - 5 } & Female & Male & Female & Male \\
\hline CI & $1.957 \pm 0.433$ & $0.627 \pm 0.041$ & $12.615 \pm 2.074^{*}$ & $4.854 \pm 1.12 *^{\mathrm{m}}$ \\
\hline GR & $0.0018 \pm 0.0001$ & $0.0045 \pm 0.0001$ & $0.404 \pm 0.094^{*}$ & $0.128 \pm 0.00 *^{\mathrm{m}}$ \\
\hline AD & $69.746 \pm 7.3168$ & $27.56 \pm 3.589$ & $80.54 \pm 2.57 *$ & $25.232 \pm 3.35 *^{\mathrm{m}}$ \\
\hline ECI & $0.5549 \pm 0.1132$ & $0.162 \pm 0.086$ & $3.1765 \pm 0.57 *$ & $1.059 \pm 0.053 *^{\mathrm{m}}$ \\
\hline ECD & $0.876 \pm 0.2513$ & $0.129 \pm 0.028$ & $3.951 \pm 0.9 *^{*}$ & $1.009 \pm 0.281 *^{\mathrm{m}}$ \\
\hline
\end{tabular}

Table 2: Some biological parameters of $H$. littoralis cohorts fed on restricted diets of clover (control cohort, C1), $N$. oleander (C2) and $N$. oleander switched to clover after 45days (C3).

\begin{tabular}{|l|c|c|c|}
\hline Parameter tested & C1 & C2 & C3 \\
\hline Preoviposion period (days) & $14.17 \pm 2.23(10-17)$ & - & $50.25 \pm 1.64(49-53)$ \\
\hline Male longevity (days) & $73.08 \pm 6.9(57-85)$ & $62.12 \pm 6.89(26-76)$ & $102.48 \pm 3.44(48-142)$ \\
\hline Female longevity (days) & $76.69 \pm 5.67(61-95)$ & $66.64 \pm 5.04(24-77)$ & $129.02 \pm 2.36(37-154)$ \\
\hline No. of egg pods/ female & $9.75 \pm 1.23(8-11)$ & - & $8.58 \pm 1.19(6-11)$ \\
\hline No. of eggs/ egg pod & $50.78 \pm 7.53^{\mathrm{a}}$ & - & $48.67 \pm 5.09^{\mathrm{a}}$ \\
\hline
\end{tabular}

\section{Discussion}

Tolerance of $H$. littoralis nymphs and adults to restricted diet of $N$. oleander had no apparent influence on their ability to survive and develop when favorable food plant became available. The insects suspended their moulting in the nymphal stage and their ovarian development in the adult stage until favorable food plant became available. $\mathrm{Nu}-$ tritional indices of $\mathrm{H}$. littoralis on oleander, as a restricted diet, were estimated during a physiologically defined period, the preoviposition period. During this period the insect exhibits high growth rates and consumes fairly large amounts of food plant under natural conditions. Nathan et al. (2005) pointed out that ECD is an index of the efficiency of conversion of digested food into body substance. The slow growth rate (GR) of $\mathrm{H}$. littoralison $N$. oleander could be attributed to the weak efficiency of conversion of ingested (ECI) and digested (ECD) food into body substance. Analysis of nutritional indices can explain the behavioral and physiological basis of insect's response to host plants (Lazarevic and Peric-Mataruga, 2003).

Heteracris littoralis, like all other acridid species, is not adapted to utilize $N$. oleander; this plant has never been reported to be selected as a food or even as a resting place by any acridid species. In the present study, the insects consumed few amounts of oleander to sustain them alive, instead of rejecting the plant and die. An important fitness indicator of insect population dynamics is body weight (Liu et al, 2004). The low CI and the extremely weak GR of $H$. littoralis on $N$. oleander indicated that, the rate of intake relative to the mean life weight during the feeding period was consistent on this plant 
during the feeding period. Meanwhile, the insects suspended their ovarian development. Suspension of ovarian development may be due to the presence of some secondary phytochemicals. Hemati et al. (2012) pointed out that Lower fitness of the pod borer, Helicover paarmigera on some host plants may be due to the presence of some secondary phytochemicals in these host plants, or absence of primary nutrients necessary for growth and development.

The level of nutrition and the timing of nutritional changes have marked effects on the reproductive output of the lubber grasshopper (Romalea microptera) (Moehrlin and Juliano, 1998). Inhibition of moulting and suspension of ovarian development in $H$. littorais may be attributed to the interference of secondary plant metabolites with the endocrine system of the insect. Some secondary plant metabolites have shown to interfere with the insect's endocrine system as protection techniques against herbivorous insects (Rosenthal and Janzen, 1979). These compounds either act as insect $\mathrm{JH}$ analogues (JHAs), or interfere with JH biosynthesis. Previously, Balsam fir juvabione was found to inhibit the metamorphosis of the linden bug, Pyrrhocoris apterus, suggesting that plants could use JHAs as defensive secondary metabolites against the insect herbivores (Bowers el al, 1966; Sláma and Williams, 1966). On the other hand, Toong et al. (1988) reported the isolation of JH III from the Malaysian plant Cyperusiria (Fa. Cyperaceae) along with the closely related compound, methyl $(2 E, 6 E)$-farnesoate; the authors found that ovaries dissected from the grasshopper (Melanopluss anguinipes) fed this plant were markedly underdeveloped compared to those of normal females, and considered the isolated compounds as defensive mechanism against insects. In Locusta migratoria, $\mathrm{JH}$ both primed the fat body and might stimulate production of vitellogenin from the hemolymph (Wyatt and Davey, 1996). Borst et al. (2000) suspected that the higher levels of JH III obser- ved at day 18 , during the oviposition cycle of $R$. microptera, stimulated vitellogenin uptake by the oocyte as a rapid rise in the oviposition index occurred. Five diterpene secondary metabolites, with juvenile hormone antagonist (JHANs), were isolated from two plants, Linderaery throcarpa and Solidago serotine, which represents an innate resistance mechanism of plants against insect herbivores (Lee et al, 2015). Authors hypothesized that JHANs, rather than JHAs, play a significant role in plant defense against insect herbivores. The drastic effect of $N$. oleander on the reproductive power of the $H$. littoralis might be attributed to the existence of strong prohibiting chemical(s) that suppressed egg formation in ovaries. Perhaps Nerium oleaner blocked the process of vitellogenesis which is controlled by juvenile hormone (Bagari et al, 2015).

Herbivores counter adaptations to allelochemical plant defenses have already been reported via several adaptive mechanisms which involve various behavioral and anatomical adaptations. A possible behavioral mechanism, involved in avoiding $N$. oleander toxic metabolites, might be that phloem feeders avoid exposure to toxic plant secondary metabolites present in mesophyll (ElShazly et al, 2000). In the present investigation, $H$. littorais exhibited a strong biotic potential, and was able to break through the defensive barriers of $N$. oleander. Adults reared on this toxic plant, not only exhibited a normal age specific survivorship curve, but they also suspended ovarian development until the food plant was switched to palatable and favorable diet, clover, and then, the insects resumed normal ovarian development with significant prolonged longevity as if, the insect was in a state of dormancy.

These results agreed with Bernays and Chapman (2000) who cited that, polyphagous grasshoppers have a relatively low level of sensitivity to the taste of many secondary compounds, and, if they did respond to the taste, have the capacity to habituate. This gives time for the induction of detoxifying 
enzymes so that unpalatable, but potentially nutritious, plants may be eaten safely. The present data showed that physiological and biochemical basis of $H$. littoralis tolerance to the defensive metabolites of $N$. oleander requires more investigations.

\section{Conclusion}

Generally speaking, the grasshoppers eat large quantities of foliage both as adults and during their development, and can be serious pests of arid land and prairies. The pasture, grain, forage, vegetable and other crops can be affected. Grasshoppers can best be prevented from becoming pests by manipulating their environment. Shade provided by trees will discourage them and they may be prevented from moving onto the developing crops by removing coarse vegetation from fallow land and field margins and discouraging thick growth beside ditches and on roadside verges.

Undoubtedly, the baits containing the predators as the protozoa are the biological control option that may be considered for the treatment of the grasshopper breeding sites. The toxic plants are also indicated in controlling these aggressive grasshoppers.

Conflict of statement: the authors declared that they neither have conflict of interest nor received funds.

\section{References}

Bagari, M, Bouhaimi, A, Ghaout, S, Chihrane, J, 2013: The toxic effects of Neruim oleander on leaves of the desert locust Schistocerca gregaria (Forskål, 1775) (Ortoptera: Acrididae). Zool. Baetica. 24:193-203.

Bagari, M, Bouhaimi, A, Ghaout, S, Chihrane, J, 2015: Toxic effects of Nerium oleander on the reproduction of the desert locust Schistocerca gregaria (Forskål 1775, Orthoptera, Acrididae). Zool. Baetica. 26:153-66.

Bernays, EA, Chapman, RF, 2000: Plant secondary compounds and grasshoppers: Beyond plant defenses. J. Chem. Ecol. 26:1773-94.

Borst, DW, Eskew, MR, Wagner, SJ, et al, 2000: Quantification of juvenile hormone III, vitellogenin, and vitellogenin-mRNA during the oviposition cycle of the lubber grasshopper. Insect Biochem. Mol. Biol. 30:813-9.

Bowers, WS, Fales, HM, Thompson, MJ,
Uebe, IEC, 1966: Juvenile hormone: Identification of an active compound from balsam fir. Science 154:1020-1.

El-Shazly, MM, 2002: Observations on oleander (Nerium oleander L., Apocynaceae) eco-system in Giza, Egypt. Proceed. $4^{\text {th }}$ Int. Conf. Urban Pests, USA.

El-Shazly, MM, El-Zayat, EM, Hermersdörfer H, 2000: Insecticidal activity, mammalian cytotoxicity and mutagenicity of an ethanolic extract from Nerium oleander (Apocynaceae). Ann. Appl. Biol. 136:153-7.

Grunshaw, JP, 1991: A revision of the Grasshopper Genus Heteracris (Orthoptera: Acrididae Eyprepocnemidinae). Nat. Resour. Inst. Bull. 38: 1-106.

Hase, GJ, Deshmukh, KK, Pokharkar, RD, Gaje, DR, Phatanagre, ND, 2017: Phytochemical studies on Nerium oleander using GC-MS. IJPPR 9:885-91.

Heller, KG, 2013: Fauna Europaea: Orthoptera. Available at: http://www.faunaeur.org

Hemati, SA, Naseri, B, Ganbalani, GN, Da-stjerdi, HR, Golizadeh, A, 2012: Effect of different host plants on nutritional indices of the pod borer, Helicover paarmigera. J. Insect Sci. 12: 55-9.

Henry, JE, 1985: Melanoplus spp. In: Handbook of Insect Rearing. Vol. 1, Singh, P, Moore, R F, (Edit.), Elsevier.

Ibrahim, MM, 1980: Development and survival of the grasshopper Heteracris littoralis Rambur on a restricted diet (Orthoptera: Acrididae). Zeitschriftfür Angewandte Entomol. 90:22-25.

Lazarevic, J, Peric-Mataruga, V, 2003: Nutritive stress effects on growth and digestive physiology of Lymantria dispar larvae. Yugoslav Med. Biochem. 22:53-9.

Lee, SH, Oh, HW, Fang, Y, et al, 2015: Identification of plant compounds that disrupt the insect juvenile hormone receptor complex. Proc. Natl. Acad. Sci. USA 112:1733-8.

Liu, ZD, Li, DM, Gong, PY, Wu, KJ, 2004: Life table studies of the cotton bollworm, Helicover paarmigera (Hübner) (Lepidoptera: Noctuidae), on different host plants. Environ. Entomol. 33:1570-6.

Longford, SD, Boor, PJ, 1996: Oleander toxicity: An examination of human and animal toxic exposures. Toxicol. 109:1-13.

Mithöfer, A, Boland, W, 2012: Plant defense against herbivores: chemical aspects. Ann. Rev. Plant Biol. 63:431-50. 
Moehrlin, GS, Juliano, SA, 1998: Plasticity of insect reproduction: testing models of flexible and fixed development in response to different growth rates. Oecologia 115:492-500.

Rosenthal, GA, Janzen, DH, 1979: In Herbivores, Their Interactions with Secondary Plant Metabolites, Academic Press: New York.

Rao, SRK, Chitra, KC, 2000: Effect of plant extracts on larval weight and duration of Spodoptera litura Fabr. J. Appl. Zool. Res. 11:98-100.

Siddiqui, BS, Sultana, R, Begum, S, Zia, A, Suria, A, 1996: Cardenolides from the methanolic extract of Nerium oleander leaves possessing central nervous system depressant activity in mice. J. Nat. Prod. 60:540-4.

Sláma, K, Williams, CM, 1966: 'Paper factor' as an inhibitor of the embryonic development of the European Bug, Pyrrhocoris apterus. Nature 210:329-30

Toong, YC, Schooley, DA, Baker, FC, 1988: Isolation of insect juvenile hormone III from a plant. Nature 333:170-1.

Waldbauer, GP, 1968: The consumption and utilization of food by insects. Adv. Insect Physiol. 5:229-88.

Wyatt, GR, Davey, KG, 1996: Cellular and molecular actions of juvenile hormone. II. Roles of juvenile hormone in adult insects. Adv. Insect Physiol. 26:1-155.

Zibbu, G, Batra, A, 2010: A review on chemistry and pharmacological activity of Nerium oleander L. J Chem. Pharm. Res 2:351-8.

\section{Explanation of figures}

Fig 1: Effect of food plant on live weight ( $\mathrm{g}$ ) of H. littoralis hoppers reared on restricted diets of $N$. oleander and T. alexandrinum (M $\pm \mathrm{S}$.E). Fig 2: Effect of food plant on length $(\mathrm{mm})$ of $H$. littoralis hoppers reared on restricted diets of $N$. oleander and T. alexandrinum $(\mathrm{M} \pm \mathrm{S}$.E). Fig 3: Weight ( $\mathrm{g}$ ) of H. littoralis hoppers reared on restricted diet of T. alexandrinum or $N$. oleander for 23 days followed by switching diet for seven days $(\mathrm{M} \pm \mathrm{S}$.E). $=$ nymphs fed on Trifoliumfor 23 days then fed on Nerium for 7 days. $\mathbf{Z U}=$ nymphs fed on Nerium for 23 days then fed on Trifolium for 7 days.

Fig 4: Length $(\mathrm{mm})$ of $H$. littorali shoppers reared on restricted diet of $T$. alexandrinum or $N$. oleander for 23 days followed by switching diet

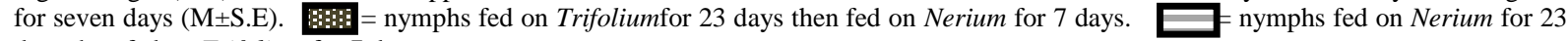
days then fed on Trifolium for 7 days.

Fig 5: Effect of food plant on the live weight (g) of grasshopper H. littoralis female adults reared on either T. alexandrium or $N$. oleander, **Highly significant $(P<0.01)$, ***Very highly significant $(P<0.001)$ between Trifolium-fed females and Nerium- fed females $(\mathrm{M} \pm \mathrm{S}$.E. $)$. Fig 6: Age specific survivorship of the grasshopper $H$. littoralis cohorts. (A): adults fed T. alexandrium, (B): adults fed $N$. oleander, and (C): adults fed $N$. oleander for 45 days before being switched to T. alexandrium.

Fig 7: Ovary of $H$. littoralis females fed on clover and Nerium for 13 days (A \& B), ovary of females fed on Nerium for 45 days(C),and eggs produced by clover and Nerium fed females (D \&E). g= germarium; 1 = lateral oviduct; o = ovary; ov =ovariole.
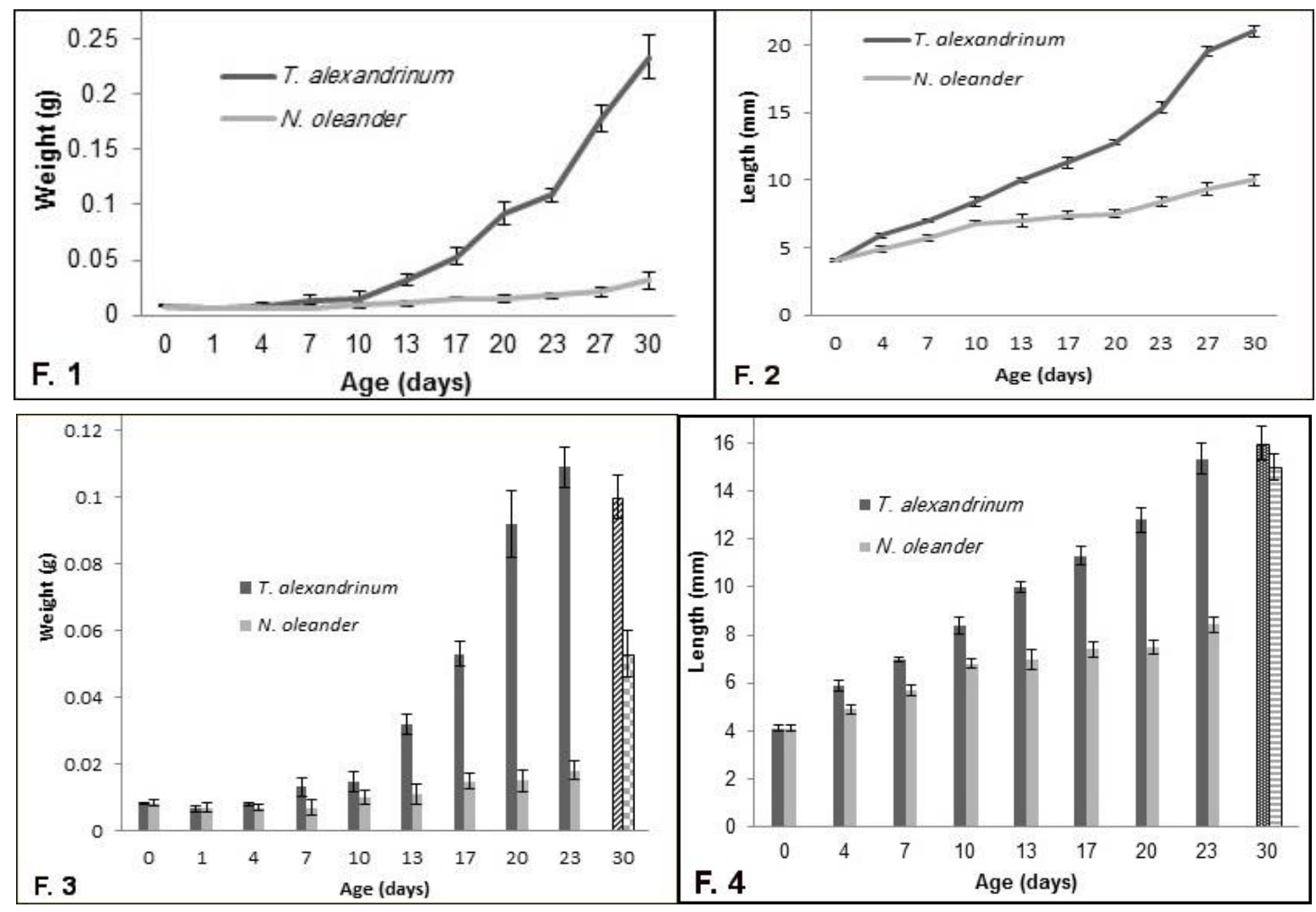

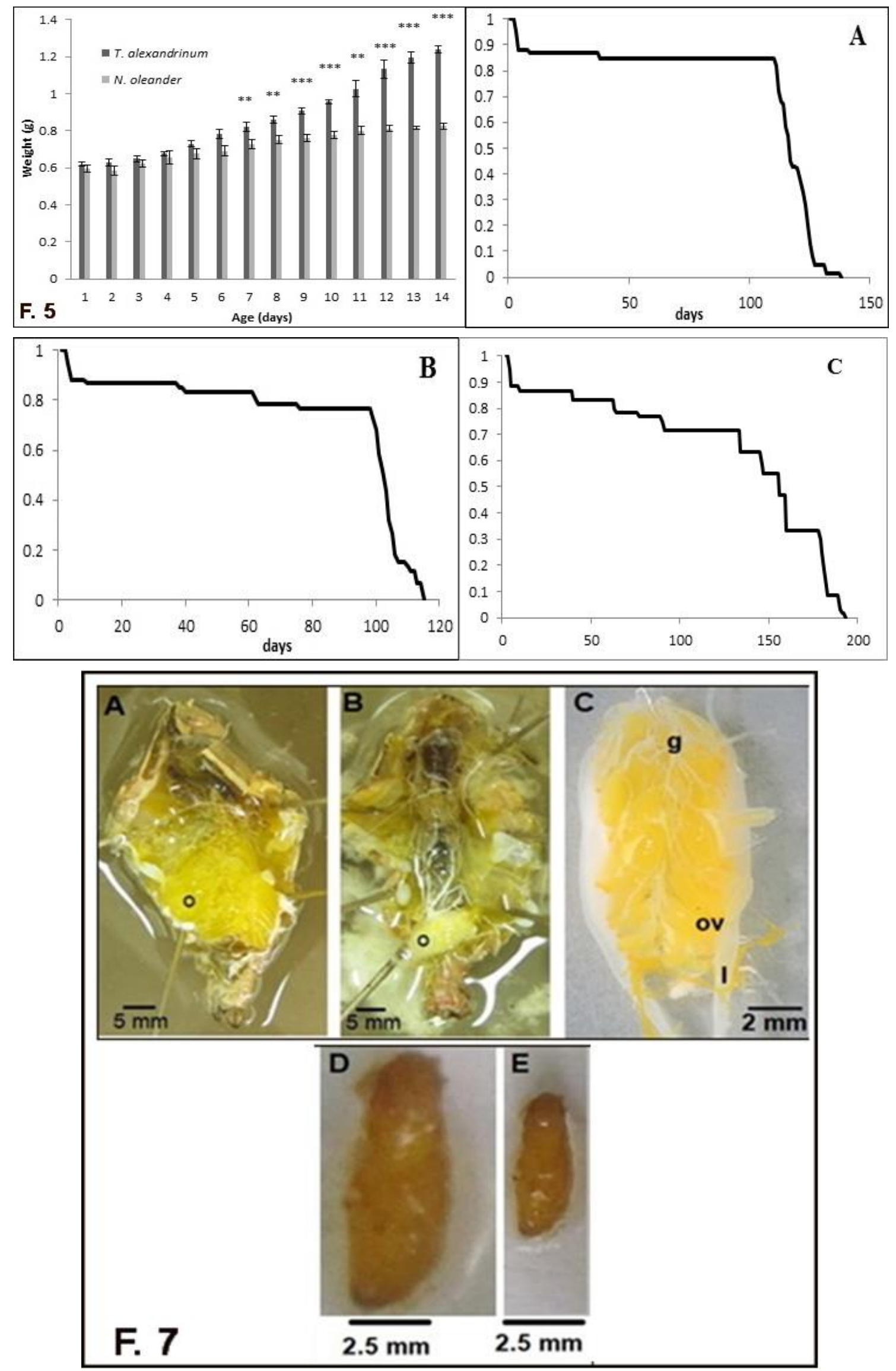